\title{
Espinheira-santa (Maytenus ilicifolia Mart. ex Reiss.): saber de erveiros e feirantes em Pelotas (RS)
}

\author{
ALMEIDA, C. ${ }^{*} ;$ BARBIERI, R.L.2; RIBEIRO, M.V. ${ }^{3}$ LOPES, C.V. ${ }^{3}$; HECK, R.M. ${ }^{3}$ \\ 1 Universidade Federal de Pelotas, Rua Gomes Carneiro no 1, CEP 96.001-970, Pelotas/RS - Brasil. ${ }^{2} E m b r a p a$ \\ Clima Temperado, BR 392, km 78, Caixa Postal 403, CEP 96.001-970, Pelotas/RS - Brasil. ${ }^{\text {UUniversidade Federal }}$ \\ de Pelotas, Rua Gomes Carneiro $n^{\circ}$ 1, CEP 96.001-970, Pelotas/RS - Brasil. *Autor para correspondência: \\ almeidakk@yahoo.com.br
}

\begin{abstract}
RESUMO: O objetivo deste trabalho é descrever o conhecimento popular relacionado à espinheira-santa (Maytenus ilicifolia) entre erveiros e feirantes que comercializam a planta no centro de Pelotas, Rio Grande do Sul, Brasil. Foi realizada uma pesquisa de abordagem qualitativa, exploratória e descritiva, de agosto a outubro de 2013. Entrevistas semi-estruturadas, com questões sobre os saberes e práticas relacionados à espinheira-santa, foram aplicadas a cinco erveiros e três feirantes do mercado informal de plantas medicinais. Para a análise dos dados foi utilizada a proposta operativa de Minayo, sendo Capra o referencial teórico para este estudo. Foi verificado que o saber relacionado ao uso da espinheira-santa é transmitido de geração a geração, embora existam outras fontes de conhecimento. As indicações do uso popular da espinheira-santa com finalidade terapêutica estão relacionadas a distúrbios gástricos, cicatrização e depuração do sangue. As diferentes formas dos sujeitos deste estudo interagirem com o ambiente, com sua família e em outras relações interpessoais resultam em diferentes saberes relacionados à espinheira-santa.
\end{abstract}

Palavras-chave: Conhecimento popular; plantas medicinais; assistência à saúde.

\begin{abstract}
Espinheira-santa (Maytenus ilicifolia Mart. ex Reiss.): knowledge by herbalists and marketers in Pelotas (RS). The aim of this study was to describe the popular knowledge related to the espinheira-santa (Maytenus ilicifolia) among herbalists and marketers that sell this plant in the center of Pelotas/Rio Grande do Sul State, Brazil. A qualitative, exploratory and descriptive research was performed between August and July of 2013. Semi-structured interviews, with questions regarding the knowledge and practices related to this plant, were applied to five herbalists and three marketers inserted in the informal market of medicinal plants. The operative proposal by Minayo was used in order to analyze the data, and the theoretical framework by Capra was used in the discussion. The popular knowledge related to the use of espinheira-santa is passed on from generation to generation, although nowadays there are other sources ofinformation. The popular clueswith therapeutic purposes are related to gastric disorders, healing and blood clearance. The study participants have different forms of interaction with the environment, the family and other interpersonal relationships, resulting in different popular knowledges related to this medicinal plant.
\end{abstract}

Keywords: Popular knowledge; medicinal plants; delivery of health care.

\section{INTRODUÇÃO}

A saúde é definida como uma sensação de bem-estar, que é resultado de um equilíbrio dinâmico e isto envolve as dimensões físicas e psicológicas do ser humano, bem como as interações advindas do ambiente natural e social (Capra, 2012). A assistência em saúde busca compreender o contexto em que estão envolvidas as pessoas, qual etapa do ciclo vital em que se encontram e principalmente como enxergam o processo saúde e doença. Valorizar a diversidade de contexto cultural possibilita uma forma de cuidado congruente e com vistas à integralidade do ser humano (Michel et al., 2010).

A intersetorialidade é uma lógica atribuída 
à gestão, considera as necessidades individuais e coletivas do cidadão e propõe romper a fragmentação das políticas (Junqueira, 1998). Essa visão de totalidade inclui as relações homem e natureza, ou seja, avalia o espaço geográfico onde ocorrem as mais diversas interações sociais. É no território que as pessoas interagem entre si e com o meio, determinando diferentes formas de agir e necessidades de serviços (Junqueira, 1998). Neste sentido, no âmbito dos serviços voltados para a saúde, encontra-se a medicina popular, uma prática contra as doenças orgânicas ou espirituais, realizada em diferentes ambientes por diferentes personagens, incluindo-se os vendedores de ervas (Albuquerque, 1997). Neste contexto, o uso de plantas medicinais é evidenciado na prevenção e tratamentos de doenças (Brasil, 2006). A utilização das plantas medicinais está atrelada à credibilidade aos resultados obtidos, à facilidade de encontrar as ervas e ao baixo custo destas (Araújo et al., 2012). Os indivíduos que abarcam saberes populares em saúde, com o uso de plantas medicinais, são possuidores de uma tradição, e o resgate histórico envolve, além da saúde individual, a saúde ambiental e a preocupação com a comunidade (Santos et al., 2011).

O comércio informal está entre as possíveis formas de acesso às plantas medicinais, além disso, é um território que envolve diferentes interações que pode estar permeada por diferentes saberes. Corroborando ao exposto, investigar este cenário contribui para o conhecimento da diversidade, do uso e do universo cultural que permeia o uso das plantas no cuidado em saúde (Azevedo \& Kruel, 2007). Os atendentes das bancas de ervas, para uso na medicina popular ou para cultos religiosos e místicos, possuem conhecimento relacionado a essas plantas e suas aplicações. Nesse contexto, os vendedores de ervas mantêm o conhecimento popular, no que tange a medicina popular e os ritos necessários a tratamento físico e espiritual dos indivíduos (Albuquerque, 1997).

No Brasil, uma grande diversidade de plantas medicinais é utilizada pela população no cuidado em saúde. Como, frequentemente, as espécies são conhecidas por diferentes nomes populares e existem várias formas de uso de acordo com a cultura estabelecida, deve haver um cuidado no uso e consumo destas plantas.

Não diferente Maytenus ilicifolia Mart. ex Reiss. é uma planta medicinal originária do Brasil, pertencente à família Celastraceae, e popularmente denominada de espinheira-santa, maiteno, cancerosa, cancorosa, cancorosa-desete-espinhos, salva-vidas, coromilho-do-campo ou, ainda, espinho-de-deus (Mariot \& Barbieri, 2007). A planta é um subarbusto que pode variar de dois a cinco metros de altura. Sua folha pontiaguda, de quatro a 12 centímetros de comprimento, é a parte utilizada com o propósito de ações nos sistemas digestório, urinário e endócrino (Lorenzi \& Matos, 2008). Os principais constituintes químicos da espinheira-santa são os terpenos, flavonóides, mucilagens, antocianos, óleos essenciais, ácido tânico, silício, sais de ferro, enxofre, sódio e cálcio, matérias resinosas e aromáticas (Macedo et al., 2007; Lameira \& Pinto, 2008; Mariot et al., 2008). Estas espécies apresentam propriedades medicinais para problemas de gastrite e úlcera gástrica comprovadas por pesquisas coordenadas pelo CEME (Central de Medicamentos) do Ministério da Saúde do Brasil (Carlini, 1988).

A forte ação antrópica sobre esta espécie, sem critérios de manejo adequados e a carência de informações com relação à caracterização de germoplasma, tem levado a perda de material vegetal, ou seja, promovendo uma importante redução demográfica das mesmas, bem como perda significativa de diversidade genética (Steenbock \& Reis, 2004; Mariot, 2005). No sentido de contribuir com o resgate do saberes que envolve a referida planta, o presente trabalho teve como objetivo descrever o conhecimento popular relacionado à espinheira-santa (Maytenus ilicifolia) de erveiros e feirantes que comercializam a planta no centro de Pelotas.

\section{MATERIAL E MÉTODO}

Trata-se de um estudo qualitativo, exploratório e descritivo (Minayo, 2010), sendo este trabalho um recorte do projeto intitulado "Saberes, Práticas em Saúde Associadas à Espinheirasanta". O projeto obteve parecer favorável junto ao Comitê de Ética e Pesquisa da Faculdade de Medicina da Universidade Federal de Pelotas sob protocolo $n^{\circ} 332.981$, bem como, foram respeitados os preceitos éticos dispostos na Resolução do Conselho Nacional de Saúde do Ministério da Saúde $n^{\circ}$ 466/12 (Brasil, 2012) e Código de Ética dos profissionais de Enfermagem (COFEN, 2007). A coleta de dados foi realizada no centro de Pelotas/RS entre agosto e outubro de 2013. Foram realizadas buscas ativas na região para identificar os vendedores de espinheira-santa. Assim, foram realizadas visitas aos estabelecimentos informais (erveiros e feirantes).

Os informantes foram identificados com a letra $E$ para erveiros e $F$ para feirantes, seguido o número da ordem das entrevistas e da idade dos entrevistados. Quando, no mesmo local, foram entrevistados dois informantes, foi informada a relação de parentesco entre eles.

Os critérios para seleção dos sujeitos

Rev. Bras. PI. Med., Campinas, v.17, n.4, supl. I, p.722-729, 2015. 
foram possuir no mínimo dois anos de experiência no comércio informal de plantas medicinais, ter conhecimento sobre espinheira-santa sob a ótica dos trabalhadores das bancas populares de comercialização de ervas ou feiras de rua, concordar em participar do estudo, bem como, com a permissão da apresentação e divulgação dos resultados nos meios acadêmicos e científicos.

A partir de um primeiro contato presencial com os possíveis sujeitos e após a explicação dos objetivos da pesquisa, estes foram convidados a participar do estudo. A efetiva participação ocorreu após o preenchimento do termo de consentimento livre e esclarecido e autorização formal do responsável de maior idade, quando o sujeito apresentava idade inferior a 18 anos. As entrevistas foram realizadas no período de expediente e no estabelecimento.

Todos os informantes optaram por responder o questionamento no instante da primeira abordagem e no local de trabalho. O número de encontros com cada informante variou de dois a três momentos. As entrevistas foram semi-estruturadas e gravadas.

A análise dos dados foi realizada conforme a proposta operativa de Minayo (2010), metodologia que utiliza três fases. A primeira é caracterizada pela ordenação dos dados, a segunda é a classificação dos dados e por fim, a análise final dos dados. $\mathrm{E}$, para fundamentar a interpretação dessas informações foi utilizado o referencial teórico de Fritjof Capra (2012).

\section{RESULTADO}

Apesar dos sujeitos possuírem a ocupação em comum, que é o comércio informal da espinheirasanta e de outras plantas medicinais, cada qual possuía um saber distinto acerca da espinheirasanta. Com o intuito de salientar estas nuanças existentes entre os oito informantes, sendo cinco ervateiros e três feirantes, a seguir estão descritas as características dos entrevistados.

E1, 65 anos, sexo masculino, descendência uruguaia, católico, referiu ter estudado até o quarto ano. Realiza a atividade de ervateiro desde sua infância, quando tinha oito anos de idade, acompanhava o pai nesta atividade. No estabelecimento, divide as tarefas com sua esposa.

E2, 24 anos, sexo masculino, não referiu descendência de imigrantes, umbandista, possui ensino superior incompleto. Divide a atividade de comércio na banca com a mãe.

E3, 17 anos, sexo masculino, referiu não possuir descendência e religião. No momento da entrevista, estava cursando o terceiro ano do ensino médio. A jornada de atendimento na banca é dividida entre pai e filho, o que denominam de "quartejo".

$\mathrm{E} 4,20$ anos atende na banca junto a sua mãe com 55 anos, ambas do sexo feminino, possuía ensino médio completo, kardecista e de descendência alemã. Presente no estabelecimento, encontrava-se a sua filha com nove meses de idade.

F1, 39 anos e seu pai com 74 anos atuam juntos na feira, ambos do sexo masculino, estudaram até o sexto e o quinto ano, respectivamente, católicos e referiram não possuir descendência. A banca comercializa especificamente plantas medicinais. O pai do F1 declarou ser o erveiro mais antigo da cidade e realiza esta atividade há 52 anos.

F3, 47 anos, sexo masculino, estudou até o sexto ano, referiu ser luterano e não possuir descendência. Este sujeito divide a atividade na feira com sua esposa e sua filha. No momento da entrevista, o feirante não possuía a espinheirasanta, pois vende a planta sob encomenda, então foi solicitada a planta, para que no próximo encontro pudesse ser adquirida. Junto a algumas plantas medicinais, o feirante vende outros produtos produzidos na sua propriedade, tais como: ovos, abóbora, feijão, beterraba, entre outros.

A fonte de conhecimento acerca da espinheira-santa é muito diversa entre os entrevistados. Quando questionados quanto a quem ensinou o que sabem sobre a planta, responderam:

"A T. me falou que já pesquisou [referindose a uma enfermeira que atua na área de plantas medicinais]. Outra senhora, que esteve há mais tempo na feira [...]. Outras pessoas já falaram que espinheira-santa é um remédio bom mesmo" (F2, 47 anos).

'[...] Foi um ervateiro (erveiro), muito antigo, trabalhava na feira, o finado J. eu aprendi o chá com ele [...]" (Pai do F1, 74 anos).

Ainda referente ao aprendizado acerca da espinheira-santa, foi muito citado que este ensinamento está inserido no núcleo familiar, sendo as figuras materna e paterna, mais evidentes e igualmente mencionadas:

"Aprendi com minha mãe, e minha mãe aprendeu com a minha avó, é de descendência [...]" (E2, 24 anos).

"Aprendi com minha mãe" (E4, 20 anos) e (Mãe da E4, 55 anos). 17 anos)

'[...] com o meu pai" (E1, 65 anos) e (E3,

No entanto, na perspectiva de aprimoramento do conhecimento adquirido, outros meios foram mencionados, como livros e a internet.

"Eu li muitos livros quando era menor, depois eu comecei a pesquisar na internet" (E3, 17 anos).

Rev. Bras. PI. Med., Campinas, v.17, n.4, supl. I, p.722-729, 2015. 
"Agora na minha geração buscamos na internet" (E2, 24 anos).

O início das atividades no comércio da espinheira-santa é precoce entre os sujeitos do estudo:

"[...] eu comecei a aprender sobre espinheira-santa com seis anos" (E3, 17 anos).

"Desde sempre [...]" (E4, 20 anos).

"[...] A minha filha se criou aqui [na banca] agora está com 20 anos, mas ela era assim [apontando para a neta que estava no carrinho]" (Mãe da E4, 55 anos).

Quando a atividade no estabelecimento é dividida entre os membros da família, o aprendizado torna-se permanente no cotidiano de convívio os familiares. Isso foi observado no momento das entrevistas os mais jovens se reportavam aos mais velhos durante a entrevista, o que está representado nas falas que seguem:

"Eu estou aprendendo, eu estou com 39, há 20 anos na feira" (F1, 39 anos).

"E... o que mais mãe? (referindo-se sobre o conhecimento que detinha sobre a planta)" (E4, 20 anos).

Quanto à indicação popular de uso terapêutico da espinheira-santa entre os informantes foram citados o uso preventivo e curativo de úlcera, tratamento de gastrite, problemas no estômago, inflamações no estômago, desconforto advindo de uma alimentação inadequada, ingestão exagerada de alimentos, refluxo, azia, promoção da cicatrização, depurativo do sangue e limpeza do sangue. No entanto, uma informante referiu que a planta possuía um disseminado mecanismo de ação:

"Ela [a espinheira-santa] age desde o esôfago, a laringe, vai até as vias urinárias, ela não é específica para o estômago, ela age no estômago, que é o principal, [...] mas ela vai agir até nas vias urinárias" (Mãe da F4, 55 anos).

No entanto, referiram que os clientes já procuraram a espinheira-santa para indicações para as quais eles desconhecem a eficácia, tais como, para a garganta e circulação do sangue. Em geral, se posicionam de modo a orientar o não uso da espinheira-santa para aquela finalidade e indicar outra planta com a requisitada propriedade:

"[...] Não adianta tomar uma coisa não sendo para aquele problema que tem [...], tem que tomar o remédio certo para o problema que está atingindo a pessoa" (F2, 47 anos).

'[...] eu tenho uma outra planta indicada para a garganta, a espinheira-santa não" (E1, 65 anos).

Três sujeitos afirmaram desconhecer o período de uso da espinheira-santa para a finalidade terapêutica. No entanto, existem disparidades entre os que recomendaram um determinado tempo de tratamento:

"Geralmente se toma assim, de 10 a 15 dias, depois se quiser dá uma pausa de uns 10 dias se quiser voltar a tomar novamente, pode" (E1, 65 anos).

'[...] Pra fazer um efeito bom, até com duas semanas de uso já faz efeito, só que toma um dia sim, um dia não. Tomando todos os dias, acostuma o organismo, aí pára de fazer o efeito" (E3, 17 anos).

"Tem horário, é todos os dias, o que a gente aconselha é tomar em princípio um pouco mais concentrado, não precisa ser tão concentrado assim. Infelizmente, pela falta de informação, as pessoas pensam que comprar um saquinho de espinheirasanta, fazer um, dois, três chás, vão ficar curadas, não é assim, é a sequência [...]" (mãe da E4).

"[...] uns meses, um ano, dois, três, tem pessoa que toma sempre, tem gente que toma 15 dias, pára, depois segue tomando de novo. Tem gente que toma de contínuo os chás" (Pai do F1, 74 anos).

"Esse pode tomar meio livre, enquanto sentir que aquele problema está te prejudicando tu deve tomar" (F2, 47 anos).

A contra-indicação da espinheira-santa é desconhecida por quase todos os sujeitos, excetuando-se um erveiro que durante a entrevista consultou um livro. Ele mantém este livro no estabelecimento para sanar as dúvidas diárias, e verificou que ali constava a advertência de consumo para gestantes. Outro informante mencionou uma advertência a respeito da interação da planta medicinal com o chimarrão, um hábito gaúcho muito comum:

"Em princípio a gente orienta que se tome puro e não no chimarrão [...] a pessoa que está fazendo tratamento com as plantas é bom que tome puro. A erva-mate pode neutralizar um pouquinho os efeitos da planta medicinal" (Mãe da E4, 55 anos).

Nas respostas dos sujeitos, foram relatadas diferentes formas de preparo. Enquanto alguns recomendam a infusão, outros indicam a decocção ou ainda relatam ser possível as duas formas de uso:

"Coloca ela [a espinheira-santa] numa vasilha com água quente, abafa e depois pode tomar à vontade" (E1, 65 anos).

"Fazer infusões, não ferver a planta, não se ferve [...] bota aí umas quatro ou cinco folhinhas para uma xícara" (Pai do F1, 74 anos).

Rev. Bras. PI. Med., Campinas, v.17, n.4, supl. I, p.722-729, 2015. 
"Tem que ser de três a cinco gramas [de espinheira-santa] pra meio litro [...]. Tanto faz [ferver ou fazer infusão], o que tu não pode é deixar fervendo [...], é que daí tu queima a erva" (E2, 24 anos).

Quando indagados quanto à procedência da espinheira-santa que comercializam, a maioria respondeu que o produto vem da colônia, ou seja, da zona rural da região. Os feirantes, apesar de não plantarem e cultivarem espinheira-santa, realizam a colheita das plantas que nascem nativas na zona rural. Um deles relatou que, apesar de não cultivar, realiza cuidados para a manutenção das plantas de onde colhe o material comercializado:

"[...] ele é preservado, a gente limpa, bota umas coisa na volta que é pra proteger"'(F2, 47 anos).

Entre os erveiros, dois indicaram realizar a colheita na natureza, e dois relataram possuir dois tipos de fornecedores: os agricultores e os laboratórios. No que tange aos cuidados tomados na colheita da espinheira-santa, os informantes relataram:

"[...] Tem que achar onde ela rebrota, senão vai quebrando, quebrando e quando vê o pé se termina [...]. Quando está recém com folhinhas novas, assim, aí tem que deixar ela se firmar" (F2, 47 anos).

"Eu mesmo que colho [...]. Eu sei de onde eu colho as minha ervas, eu não gosto de colher na beira de estrada, em beira de lavoura também não se colhe. Então, se vou comprar uma erva e eu não sei de onde é que está pegando, pode estar pegando de beira de estrada, ou se é de beira de lavoura de arroz ou soja, isso é um perigo por causa do veneno que usam" (Pai do F1, 74 anos).

"[...] Tem que tirar com calma, devagar, os espinhos machucam bastante os dedos" (E3, 17 anos).

Quanto à secagem da espinheira-santa a partir de material fresco, tanto com relação ao originário da colheita direta como aquele adquirido de fornecedores, os sujeitos referiram processar a planta das seguintes formas:

"Essa secagem é feita com tela. A gente coloca em tela, que é pra ficar bem arejada, [...] na sombra" (E1, 65 anos).

"Eu trago fresca [referente à espinheirasanta] [...]. Às vezes, quando eu vejo que a pessoa não vem buscar [...], eu seco ela na sombra [...]. Aquela folhagem bota ela num pacote, que não pode ser plástico, tem que ser um pacote de papel [...]" (F2, 47 anos).

"Coloca em caixinhas de plástico, e deixa no sol" (E2, 24 anos).

\section{DISCUSSÃO}

O emprego das plantas medicinais no cuidado à saúde tem sua origem alicerçada no acúmulo de saberes, que são transmitidos a cada geração (Brasil, 2006; Ceolin et al., 2011). Não diferente disso, este estudo apontou como principal fonte de conhecimento acerca da espinheira-santa o núcleo familiar, embora também existam outras vertentes de saberes, como livros e internet, mencionados pelos entrevistados deste estudo.

A precocidade dos sujeitos, no início das atividades de comércio informal da espinheirasanta, o permanente aprendizado dos mais jovens e o saber do mais velho posto como soberano ao do mais jovem são constatações que podem estar atreladas à cultura e a aspectos sociais. Corroborando ao exposto, o comércio informal de plantas está relacionado a práticas populares de saúde, a crença e a tradição (Quintana \& Oliveira, 2012). Sob a interpretação do referencial adotado neste estudo, estes fatores podem ser considerados como um produto resultante da história deste determinado contexto ambiental e cultural (Capra, 2012).

Na medicina popular, existem diferentes indicações para a espinheira-santa. O tratamento da gastrite com o uso da planta teve sua eficácia confirmada cientificamente (Cipriani et al., 2006; Baggio et al., 2007). A diversidade do uso popular, incluindo a utilização para fins de emagrecimento, depuração do sangue, tratamentos de problemas de bexiga, problemas renais, problemas ou dores estomacais, tratamento de úlceras do estômago, gastrite, diabetes e problemas intestinais já foi demonstrada em outros estudos (Mariot \& Barbieri, 2007; Macedo et al., 2007; Mariot et al., 2008). Ao que tange a concepção ecológica de Capra (2012), a diversidade no uso da espinheira-santa pode estar atrelada às diferentes inter-relações das partes, ou seja, nas diferentes experiências vivenciadas entre os indivíduos e na forma como se relacionam entre si e com o ambiente.

O fato de algumas indicações dos clientes para a espinheira-santa divergirem do conhecimento dos erveiros e feirantes entrevistados, pode estar relacionado a diferentes acúmulos de saberes referentes à planta, o que por sua vez, pode estar vinculado a diferentes formas de interação com a natureza. O ser humano é o resultado de várias relações, de vertentes sociais, físicas e emocionais, no entanto, essa sua condição de ser ator de inúmeras relações proporciona a possibilidade de modificar ou modificar-se (Capra, 2012).

Nos relatos dos informantes não há uma recomendação única de preparo, inclusive foi mencionada uma possibilidade de flexibilidade na

Rev. Bras. PI. Med., Campinas, v.17, n.4, supl. I, p.722-729, 2015. 
forma de utilização da espinheira-santa. Os sujeitos não relataram propriedades indesejadas do uso da planta e apenas um referiu contra-indicação. Essa diversidade de informações, denominada por Capra (2012) de conhecimento subjetivo, é o que devemos resgatar no atual modelo de saúde, segundo o autor as doses e manejos referentes às terapias devem ser determinados de acordo com a resposta do paciente. No entanto, a Resolução de Diretoria Colegiada (RDC) $n^{\circ} 10 / 2010$ foi publicada com intuito de garantir a segurança no uso de plantas medicinais, com normativas referentes à produção, distribuição e consumo. No documento constam a dosagem, a forma de preparo e as contra-indicações, dentre outras recomendações. No caso da espinheira-santa, é recomendada a infusão das folhas, na proporção de um a dois gramas para 150 mililitros de água, sendo a posologia, uma xícara de chá de três a quatro vezes ao dia. O uso é contra-indicado para menores de seis anos de idade e mulheres no primeiro trimestre gestacional (Brasil, 2010).

Apesar de não ter sido encontrado na literatura, a recomendação do período de tratamento utilizando especificamente a espinheira-santa, Brasil (2010) recomenda que o uso seja episódico, ou seja, com intuito de aliviar os sintomas das doenças de baixa gravidade, e intermitente, por período limitado de tempo, porém não determina um valor quantitativo.

Devido à escassez de estudos mais aprofundados referentes ao período de tratamento recomendado com a espinheira-santa, fica evidente a importância da ampliação de pesquisas relacionadas a esta lacuna. A informação referente à duração da terapia com uso de plantas medicinais é uma importante contribuição para os profissionais da saúde. Entretanto, segundo Capra (2012) esta seria uma preocupação quantitativa, sem demérito da mesma, mas é necessário amparar a abordagem em saúde na consciência que cada pessoa é um sistema diferente e responderá diferentemente a cada terapêutica.

O mercado informal de plantas medicinais é constituído de diferentes atores: os coletores, os atravessadores e os erveiros (Alves et al., 2008). Os atendentes das feiras e bancas de ervas do centro de Pelotas desempenham apenas as atividades de coleta e de venda da espinheira-santa. Os que coletam não informaram com precisão o local de colheita, talvez o receio em divulgar a origem esteja atrelado ao número reduzido de plantas nativas. Pois, nesta abordagem, demonstraram uma interação com o ambiente, entretanto nem sempre acompanhada de uma preocupação com a sustentabilidade, ao menos evidenciaram uma interação de cuidado com a natureza, percebendo- se como parte responsável pelo equilíbrio, de acordo com pressuposto de Capra (2012).

A secagem das plantas medicinais está diretamente relacionada à manutenção das propriedades medicinais. No caso da espinheirasanta, em que a parte manuseada no preparo são as folhas, em que devem permanecer à sombra após a colheita, em local arejado e coberto, dispostas em camadas finas que devem ser remexidas eventualmente. $O$ processo de secagem, nestas condições, dura de três a cinco dias, mas também pode ser realizado com auxílio de estufa e microondas (Lorenzi \& Matos, 2008). Considerando essa metodologia, pode-se verificar que os feirantes e erveiros entrevistados detêm esse conhecimento, e apenas um deles demonstrou utilizar um procedimento inadequado, secando as folhas ao sol.

\section{CONCLUSÃO}

Os erveiros e feirantes que comercializam espinheira-santa no centro de Pelotas/RS detêm um conhecimento herdado de outras gerações familiares, possuindo algumas semelhanças (fonte do conhecimento, manutenção do conhecimento) e diferenças (formas de uso, período de tratamento, indicação de uso), fato que pode estar relacionado às diferentes formas de interação dos sujeitos este estudo. Dessa diversidade de relações, constituemse saberes que são perpetuados pelas próprias interações com o ambiente, com a família e outras relações interpessoais.

Os erveiros além de venderem as plantas, detêm um conhecimento relacionado à cura de doenças e, com isso, tornam-se referência para alguns indivíduos ao que tange a medicina popular. Esse trabalho evidenciou a necessidade de realizar um resgate cultural no âmbito do comércio informal da espinheira-santa, a fim de compreender os saberes populares relacionados ao cuidado em saúde. A compreensão desses saberes pode contribuir para a resolubilidade do sistema em saúde, estimulando a participação social nas políticas em saúde e a diminuição da medicalização.

Outros estudos deveriam ser realizados com o intuito de investigar detalhadamente a procedência da espinheira-santa disponibilizada pelos erveiros e feirantes no centro de Pelotas/RS e, de caráter farmacológico, o período de tratamento seguro e eficaz ao que tange o uso da espinheira-santa. Apesar dos sujeitos dividirem seus saberes durante as entrevistas, dentre aqueles que realizavam a atividade de coleta não foi demonstrado interesse em informar com exatidão a origem das plantas disponibilizadas, sendo que o motivo da recusa pode estar relacionado ao medo de diminuição do

Rev. Bras. Pl. Med., Campinas, v.17, n.4, supl. I, p.722-729, 2015. 
material, uma vez que referiram não ser abundante o quantitativo desta planta.

\section{REFERÊNCIAS}

ALBUQUERQUE, U.P. As plantas medicinais e mágicas comercializadas nos mercados públicos de RecifePE. Ciência \& Trópico, v.25, n.1, p.7-15, 1997. Disponível em: http://periodicos.fundaj.gov.br/CIC/ article/view/642/428. Acesso em: 12 abr. 2011.

ALVES, R.R.N. et al. Aspectos sócio-econômicos do comércio de plantas e animais medicinais em áreas metropolitanas do Norte e Nordeste do Brasil. Revista de Biologia e Ciências da Terra, v.8, n.1, p.181-9, 2008. Disponível em: http://www.redalyc.org/ pdf/500/50080120.pdf. Acesso em: 20 jan. 2013.

ARAÚJO, K.R.M. et al. Plantas medicinais no tratamento de doenças respiratórias na infância: uma visão do saber popular. Revista da Rede de Enfermagem do Nordeste, v.13, n.3, p.659-66, 2012. Disponível em: http://www.revistarene.ufc.br/revista/index.php/revista/ article/view/733/pdf 1. Acesso em: 12 jan. 2013.

AZEVEDO, V.M; KRŪEL, V.S.F. Plantas Medicinais e ritualísticas vendidas em feiras livres no Município do Rio de Janeiro, RJ, Brasil: estudo de caso nas zonas Norte e Sul. Acta Botânica Brasilica, v.21, n.2, p.26375, 2007. Disponível em: http://www.scielo.br/pdf/abb/ v21n2/02.pdf. Acesso em: 10 abr. 2011.

BAGGIO, C.H. et al. Flavonoid-rich fraction of Maytenus ilicifolia Mart. ex. Reiss protects the gastric mucosa of rodents through inhibition of both $\mathrm{H}+, \mathrm{K}+$-ATPase activity and formation of nitric oxide. Journal of Ethnopharmacology, v.113, n.3, p.433-40, 2007.

BRASIL. Ministério da Saúde. Conselho Nacional de Saúde - Resolução n $^{\circ} \mathbf{4 6 6}$ de 12 de dezembro de 2012. Brasília. Disponível em: http://conselho.saude. gov.br/resolucoes/2012/Reso466.pdf. Acesso em: 13 out. 2013.

BRASIL. Ministério da Saúde. Secretaria de Atenção à Saúde. Departamento de Atenção Básica. Política Nacional de Práticas Integrativas e Complementares no SUS. Brasília, 2006.

BRASIL. Ministério da Saúde. Agência Nacional de Vigilância Sanitária (ANVISA). Resolução RDC $\mathbf{n}^{\circ} 10$ de 09 de março de 2010. Disponível em: http://www. brasilsus.com.br/legislacoes/rdc/103202-10. Acesso em: 30 jul. 2012.

CAPRA, F. O ponto de mutação. 30.ed. São Paulo: Cultrix, 2012. 429p.

CARLINI, E. A. (Coord.). Estudo da ação antiúlcera gástrica de plantas brasileiras: Maytenus ilicifolia (espinheira-santa) e outras. Brasília: CEME/AFIP, 1988. 87p.

CEOLIN, T. et al. Plantas medicinais: transmissão do conhecimento nas famílias de agricultores de base ecológica no Sul do RS. Revista da Escola de Enfermagem da USP, v.45, n.1, p.47-54, 2011. Disponível em: http://www.scielo.br/pdf/reeusp/ v45n1/07.pdf. Acesso em: 12 fev. 2012.

CIPRIANI, T.R. et al. A polysaccharide from a tea (infusion) of Maytenus ilicifolia leaves with anti-ulcer protective effects. Journal of Natural Products, v.69, n.7, p.1018-
21, 2006

COFEN. Conselho Federal de Enfermagem. Código de Ética dos Profissionais de Enfermagem. Resolução COFEN n³11 de 08 de fevereiro de 2007. Disponível em: http://www.portalcofengov.br/2007/materias.asp?A rticleID=7323\&sectionID=37. Acesso em: 18 out. 2012.

JUNQUEIRA, L.A.P. Descentralização e intersetorialidade: a construção de um modelo de gestão municipal. Revista de Administração Pública, v.32, n.2, p.1122, 1998. Disponível em: http://bibliotecadigital.fgv.br/ ojs/index.php/rap/article/viewArticle/7696. Acesso em: 18 mar. 2012.

LAMEIRA, O.A.; PINTO, J.E.B.P. Plantas Medicinais: do cultivo, manipulação e uso à recomendação popular. 1.ed. Belém: Embrapa Amazônia Oriental, 2008. 264p.

LORENZI, H.; MATOS, F.J.A. Plantas medicinais no Brasil nativas e exóticas. 2.ed. Nova Odessa: Instituto Plantarum, 2008. 544p.

MACEDO, A.F. et al. Ocorrência do uso de plantas medicinais por moradores de um bairro do município de Marília-SP. Revista de Ciências Farmacêuticas Básica e Aplicada, v.28, n.1, p.123-8, 2007. Disponível em: http://serv-bib.fcfar.unesp.br/seer/index.php/Cien_ Farm/article/view/354/339. Acesso em: 18 mar. 2012.

MARIOT, M.P. Recursos genéticos de Espinheira-Santa (Maytenus ilicifolia e Maytenus aquifolium) no Rio Grande do Sul. 2005. 125p. Tese (Doutorado - Área de Concentração em Fitomelhoramento) - Departamento de Fitotecnia, Universidade Federal de Pelotas, Pelotas.

MARIOT, M.P.; BARBIERI, R.L. O conhecimento popular associado ao uso da Espinheira-Santa (Maytenus ilicifolia e M. aquifolium). Revista Brasileira de Biociências, v.5, supl.1, p.666-8, 2007. Porto Alegre. Disponível em: file:///C:/Users/COREN-RS/ Downloads/677-2668-1-PB\%20(1).pdf. Acesso em: 20 mar. 2012

MARIOT, M.P. et al. Variabilidade em matrizes de acessos de espinheira-santa. Ciência Rural, v.38, n.2, p.351-7, 2008. Disponível em: http://www.scielo.br/pdf/cr/v38n2/ a09v38n2.pdf. Acesso em: 12 fev. 2012

MICHEL, T. et al. As práticas educativas em enfermagem fundamentadas na teoria de Leninger. Cogitare Enfermagem, v.15, n.1, p.131-7, 2010. Disponível em: http://ojs.c3sl.ufpr.br/ojs/index.php/cogitare/article/ viewArticle/17184. Acesso em: 18 mar. 2012.

MINAYO, M.C.S. O desafio do conhecimento: pesquisa qualitativa em saúde. 12.ed. São Paulo: HUCITEC, 2010. 407p.

PELOTAS. Prefeitura Municipal de Pelotas. Lei municipal $\mathrm{n}^{\circ} \mathbf{5 . 4 9 0}$, de 24 de julho de 2008. Dispõe sobre a delimitação dos distritos do município de Pelotas e das regiões administrativas do seu distrito sede (zona urbana), e dá outras providências. Disponível em: <http://www.pelotas.rs.gov.br/cidade/dados-gerais. php>. Acesso em: 18 dez. 2012.

QUINTANA, H.T.; OLIVEIRA, M.W. Morar e trabalhar na mesma comunidade: a visão de praticantes populares de saúde. Revista de Atenção Primária à Saúde, v.15, n.4, p.454-467, 2012. Disponível em: http://aps.ufjf. emnuvens.com.br/aps/article/view/1694/678. Acesso em: 20 abr. 2013.

SANTOS, M.C. et al. Resgate histórico de um grupo rural de estudos das plantas medicinais: educação em 
saúde. Cadernos de Educação FaE/PPGE/UFPel, v.39, p.285-99, 2011. Disponível em: http://www. researchgate.net/publication/266507348_Resgate_ histrico_de_um_grupo_rural_de_estudos_das_plantas_ medicinais_educao_em_sade. Acesso em: 25 jul. 2014 .
STEENBOCK, W.; REIS, M.S. Manejo de populações naturais de Espinheira Santa. In: REIS, M.S.; SILVA, S.R. (Ed.). Plantas medicinais e aromáticas: Espinheira Santa. Brasília: Editora IBAMA, 2004, p.145-61.

Rev. Bras. PI. Med., Campinas, v.17, n.4, supl. I, p.722-729, 2015. 